\title{
Tradición y política en la formación religiosa de los grupos judíos del siglo II a.C.
} a siglo I d.C

\begin{abstract}
Tradition and Politic in the religious formation of the Jewish groups of the second century BCE to the first century CE.
\end{abstract}

Fernando Mattiolli Vieira

DOI: https://doi.org/10.24215/22505121e050

Universidad de Pernambuco, Brasil

khirbet.qumran@gmail.com.

Recepción: 05 Marzo 2020

Aprobación: 25 Junio 2020

\section{ReSUMEN:}

Los grupos judíos desde el siglo II a.C. hasta el siglo I d.C. se han considerado en las últimas décadas por una perspectiva aproximativa, comenzando principalmente por las características comunes entre ellos. Muchos de ellos provienen de tradiciones antiguas, presentes en textos sagrados de alcance nacional. Sin embargo, otros no tienen paralelo en la historia bíblica, pero están presentes entre los grupos de ese período. El propósito de este artículo es mostrar que estas características no son el resultado de préstamos, sino que son el resultado de la presión política que nivela las experiencias religiosas y sociales de todos los grupos que estuvieron presentes en una red amplia y estructurada de interdependencias.

Palabras ClaVe: Grupos, Tradiciones, Política, Experiencia religiosa y social.

\section{Abstract:}

The Jewish groups from the second century $B C E$ to the first century CE have been considered in the last decades by an approximate perspective, starting from the common characteristics among them. Many of them come from the ancient traditions, present in the sacred texts of national scope. However, others have no parallel in biblical history, but are present among groups of that period. The purpose of this article is to show that these characteristics are not the result of borrowings, but result from the political pressures that leveled the religious and social experiences of all those groups that were present in a wide and structured network of interdependencies.

KeYwords: Groups, Traditions, Politics, Religious and Social Experience.

\section{INTRODUCCIÓN}

Entre el siglo XIX y mediados del siglo XX, lo que más interesó a los investigadores que se dedicaron al estudio de grupos judíos del periodo del Segundo Templo, promovidos principalmente por intereses religiosos (porque ese era el entorno para el nacimiento de dos grandes religiones importantes para el Occidente), fueron las innovaciones de cada grupo, comprendidas en la historiografía como elementos singulares que llamaron la atención por la creatividad principalmente en los campos religioso y social. Con el descubrimiento de nuevas fuentes y la creación de nuevos métodos y enfoques históricos en el curso del siglo $\mathrm{XX}$, las “similitudes" entre esos grupos se están convirtiendo en un valioso objeto de estudio. Estas similitudes revelan que la "distancia" entre ellos, con respecto a las experiencias religiosas y sociales, es mucho menor que la concebida durante mucho tiempo. El ethos comunitario fue el resultado de un patrimonio cultural común, compartido por todos los segmentos de la sociedad judía. Por otro lado, hubo elementos de naturaleza política que hicieron que estas experiencias fueran muy cercanas. ${ }^{1}$

Para tal trabajo, es necesario llevar a la discusión cómo se pueden caracterizar esas pequeñas unidades sociales del período. La historiografía que trata de los estudios judíos registra varias formas de definirlos: clubes, sociedades de ayuda mutua, gremios, asociaciones, escuelas filosóficas, facciones, partidos, filosofías, entre las más conocidas. Las bases para la conceptualización utilizada por los investigadores son, en general, su 
extensión (pequeña o grande) y su representación (menor o mayor) en el entorno social. El concepto utilizado para referirse a ellos es de gran importancia, ya que puede afectar los estudios históricos sobre sus límites en la sociedad. ${ }^{2}$ Las complicaciones derivadas de un enfoque incorrecto pueden ejemplificarse utilizando el concepto "secta", que todavía está presente en la investigación actual. Su uso proviene de estudios modernos que reflejaron algunas de esas colectividades por conceptos muy prejuiciosos. Aquí, elijo llamarlos "grupos", un concepto amplio que no los distancia del entorno social y que al mismo tiempo les permite ser entendidos como activos en una amplia red de interdependencias.

Otra consideración importante que debe hacerse al principio está relacionada con la identidad de los grupos considerados. Estamos tratando, sobre todo, de un contexto judío específico, pero en un espacio completamente entrelazado por relaciones culturales y políticas de orígenes helenística y romana, un hecho que muchas veces no es considerado en la investigación sobre el tema (Guarinello, 2014: 47-57). No solo hubo grupos judíos en territorio judío entre los siglos II a.C. y I d.C. Por el contrario, también sabemos que había grupos de matriz judía fuera de la Judea (como veremos más adelante con el uso de las fuentes). Para responder a esto, tomé prestada la propuesta de Albert Baumgarten (1998: 93), que divide grupos desde Egipto hasta Asia Menor en dos segmentos básicos: judíos y grecorromanos. La diferencia central entre ellos es que los judíos se guiaron por el ideal religioso de la Alianza (berit) y las tradiciones vinculadas al pasado bíblico, mientras que los grecorromanos se parecían a escuelas filosóficas, principalmente con una base epicúrea, estoica y pitagórica. Sin embargo, con respecto a sus experiencias religiosas y sociales, todos tenían características muy comunes, como códigos de conducta, comidas comunitarias simbólicas, procesos para admitir nuevos miembros, reuniones, etc. El enfoque de este análisis se limitará a grupos de matriz judía, mientras que los grecorromanos se utilizarán para la comparación.

Las fuentes más conocidas de la época, como los libros del historiador judío Flavio Josefo (siglo I d.C.), los Rollos del Mar Muerto (siglo II a.C. a I d.C.), la Mishná (siglo I a.C. a III d.C.) y los textos bíblicos canónicos cristianos (del siglo I d.C. al II d.C.) nos hablan de grupos que ocuparon espacios importantes en la sociedad judía de los siglos II a.C. a I d.C., como los fariseos, saduceos y esenios, que se originaron en disputas del poder político y religioso durante el período en que se estableció el gobierno macabeo (c. 152 a.C.). Sin embargo, a partir de ese momento hubo una proliferación de grupos de las más diversas orientaciones, lo que parece mantener un movimiento creciente hasta el siglo I d.C., trayendo a la escena social grupos como gnósticos, bautistas (Hch 18: 25, 19: 1-5), judeocristianos $\left(\operatorname{Hch}^{3} 24: 5\right)$, herodianos (Ma 3: 6, 12: 13) y la "cuarta filosofía" (AJ 18: 3-10, 23-25 $)^{5}$.

La naturaleza y la configuración de estos grupos son heterogéneas. Constantemente caemos en la tentación de definirlos como unidades monolíticas, con la acción social limitada a un campo específico. Por el contrario, los saduceos, por ejemplo, siempre recordados en la historiografía por componer un grupo religioso con ideas opuestas a las de los judeocristianos, parecen haber estado mucho más interconectados por los poderes político y económico que por cualquier doctrina religiosa en particular ("no pueden persuadir a nadie más que a los ricos"6 [AJ 13:298]), considerando su papel a la frente de los sistemas político y judicial de la época. Casos como este muestran cuán arriesgado es asignar una naturaleza específica a un grupo. Es menos incierto afirmar que sus actividades fueron dirigidas de acuerdo con determinaciones políticas y contradicciones sociales presentes en esa sociedad que estaba experimentando intensas transformaciones. ${ }^{7}$

Lo que nos ayuda a comprender la posición de esos grupos, si fueron judíos o grecorromanos, es el hecho de que los propios historiadores judíos del siglo I d.C., como Flavio Josefo y Filón de Alejandría, los consideraron por la perspectiva de la proximidad, un hecho que, en lugar de resaltar las discrepancias entre ellos, destacó las similitudes. Josefo declaró que los esenios "no viven de una manera diferente, sino similar a la de los dacios, llamados Ctistae” (AJ 18: 22). Él también acercó los esenios a los pitagóricos (AJ 15: 371) y los fariseos a los estoicos (Vita 12). Las similitudes señaladas por Josefo se encuentran principalmente con respecto a la experiencia religiosa, como la perspectiva de la inmortalidad del alma (GJ 2: 154-157), sobre los sacrificios 
y la importancia dada a los calendarios. Filón, a su vez, no apunta a una comparación directa entre ellos, pero sus descripciones comienzan con supuestos comunes a todos. Por ejemplo, uno de sus escritos, De Vita Contemplativa, habla sobre un grupo egipcio llamado "terapeutas" (del grego therapeutae). Debido a que su descripción tiene elementos similares a los atribuidos a los esenios, como el régimen comunitario, el desprecio por la riqueza material y la reverencia por el sábado, los historiadores creen que Filón pudo haberse referido a un grupo de judíos esenio-egipcios o algún otro de matriz judía. ${ }^{8}$

La multiplicidad de grupos de carácter religioso es la prueba más evidente de que la religión judía estuvo lejos de tener una unidad hasta finales del siglo I a.C. Grupos dominantes que estaban entrelazados en el poder y, por lo tanto, vinculados a una "religión del Templo", no tenían la autoridad suficiente para imponer un aspecto particular de la religión en toda la nación. El papel de las masas campesinas también llama la atención, poco recordado por los investigadores debido a sus pocas referencias textuales. Richard Horsley (1985: 8) nos recuerda que solo el 10\% (o tal vez menos) de la población estaba directamente relacionada con algún grupo judío importante en el siglo I d.C. La gran mayoría de la población no compartió experiencias religiosas "muy elaboradas", con una base teológica profunda, encontrada principalmente entre los grupos letrados. Por el contrario, se basó en elementos culturales presentes en la sociedad, que llegaron a formar una experiencia religiosa más vinculada a una religiosidad campesina, con participación en festividades nacionales (Ex 23: 14-17; 2Cr 8: 13) y con la ofrenda de sacrificio en el Templo cuando viajaba a Jerusalén (Lc 2:41). Sin embargo, las masas campesinas también desempeñaron un papel político importante en períodos problemáticos, como durante la lucha contra los seléucidas de Siria en el siglo II a.C., junto con los macabeos, y en las décadas anteriores a la Primera Guerra Judía entre 66-74 d.C., debido al estrangulamiento económico impuesto por Roma. En ambas situaciones, nacieron grupos específicos de aspiraciones políticas y religiosas.

\section{TRADICIÓN Y POLÍTICA Y LA INTERPRETACIÓN DE LAS SIMILITUDES}

Frente a un escenario social parcialmente reconstruido, lo que debe hacerse ahora es señalar el material cultural utilizado para la composición de esos grupos judíos. Es posible identificar dos tipos: el primero es la tradición, que se encuentra en los libros sagrados y que, por intereses particulares, se ha reformulada continuamente para atender sus necesidades. El segundo es la política. Esto estaba sujeto a un juego complejo, que involucraba agentes internos y externos, que colocaba a Judea en medio de un contexto geopolítico más amplio, primero como parte del mundo helenístico y después romano. La forma de organización de esos grupos estaba limitada por la situación política y los elementos que prueban que no se pueden encontrar en el pasado bíblico venerado por los judíos. Las similitudes de esta naturaleza son bastante interesantes porque no se encuentran precedentes en la historia judía y porque acercan a los grupos religiosos judíos a los grecorromanos. Son interpretados de las más variadas formas por los historiadores contemporáneos y serán los más explorados en este artículo.

Hablemos brevemente sobre las tradiciones utilizadas como fuente para los grupos judíos. Parte de la historia del pueblo judío, lo que se considerará sagrado, se encuentra en las tradiciones bíblicas, aceptadas durante el siglo II a.C. a I d.C. como una historia oficial gracias a la autoridad de los textos bíblicos. En esos siglos, incluso antes de la formación del canon bíblico esbozado por el judaísmo rabínico, los libros que compondrían la Torá ya eran aceptados como canónicos (Schniedewind, 2004: 195-196). ${ }^{9}$ Los escritos creados por los grupos letrados presentan reinterpretaciones de estos textos antiguos, que fueron adaptados de acuerdo con las condiciones sociopolíticas de la época. Los usos del pasado para elementos centrales de las tradiciones judías, como la observación del sábado, las reglas de pureza y la interpretación de la ley en general, campos en los que se encontraron las mayores diferencias entre los grupos judíos, promovieron el sustrato ideológico de esos grupos, mientras que, por otro lado, dieron como resultado características más o menos auténticas en sus experiencias religiosas y sociales. 
Desde una perspectiva histórico-institucional, el papel desempeñado por la institución más importante del judaísmo, el Templo de Jerusalén, muestra la proximidad de los grupos de matriz judía en los aspectos religiosos y sociales. ${ }^{10}$ Aunque los grupos judíos compitieron por el monopolio de la interpretación de las tradiciones con los líderes del Templo, la mayoría de ellos reconoció esta institución como un símbolo religioso nacional. ${ }^{11}$ El Templo fue dirigido por el grupo de los saduceos (Hch 5: 17), quienes formaron una élite aristocrática que se elevó al dominio político de las instituciones judías en el siglo II a.C. Sin embargo, a otros segmentos no se les impidió participar en las actividades religiosas previstas en el calendario judío. Los fariseos eran la oposición más fuerte a los saduceos, pero tenían el Templo abierto para hacer sacrificios y participar en discusiones con los saduceos. Los esenios, narrados por Flavio Josefo, enviaron ofrendas al Templo, pero hicieron sus sacrificios de manera diferente a otros grupos judíos (AJ 18: $19^{12}$ ). Los judeocristianos, según el escritor Lucas, aprovecharon el entorno común del Templo para predicar (Hch 5: 20-21, 42). El Templo de Jerusalén nos ayuda a comprender que todos esos grupos, mientras mantienen rivalidades religiosas y políticas, comparten una base histórica y social común. ${ }^{13}$

La proximidad entre los grupos judíos se hace bastante clara por los usos que hicieron del pasado, pero las similitudes que no tenían esta base llaman la atención y causan cierta extrañeza. Lo más interesante es que estas similitudes no se encuentran solo entre los grupos de matriz judía, pero son compartidas también con los grecorromanos (y hasta con los más sincréticos, formados por judíos de pensamiento helenístico). Se encuentran varias otras características entre esos grupos, tales como: el carácter de hermandad, la voluntariedad (en lugar del nacimiento), los ritos de iniciación, la necesidad de aprehender el conocimiento para la ascensión jerárquica, el secreto con respecto al conocimiento del grupo ante el medio social, comidas, el sistema legal y judicial, doctrinas, libaciones, incienso, sacrificios, etc. Definitivamente no hay espacio para que discutamos cada uno de estos elementos en este momento. ${ }^{14}$ Sin embargo, el interés principal es comprender lo que hay detrás de todas estas similitudes.

Algunas propuestas ya han estado presentes en la historiografía, especialmente en las últimas décadas, para explicar las similitudes entre los grupos de la época. Destacaré tres de ellas, las que creo ser las más importantes, utilizando un autor influyente de cada una. El primero se basa en el mecanismo de "influencia". Los historiadores han señalado estas influencias en muchos aspectos, presentes principalmente en los campos lingüístico, literario, doctrinal y organizativo. Las principales fuentes de influencia habrían venido del intercambio de experiencias con grupos grecorromanos, que habrían insertado elementos desconocidos en la sociedad judía, pero que eran comunes en el mundo helenístico. En este sentido, un gran nombre fue el del historiador alemán Martin Hengel. Su enfoque principal fue el estudio de las influencias helenísticas en los grupos de matriz judía. Parte de sus consideraciones se hicieron sobre el esenismo y la Yahad (siguiendo el gran impulso de la investigación académica que ocurrió con el descubrimiento de los Rollos del Mar Muerto en 1947). Afirma que el Maestro de Justicia, el líder fundador de Yahad, podría haber conocido prácticas comunes en las escuelas pitagóricas e introducido estándares de educación griegos al grupo (1974: 246). Esto se encontraría, por ejemplo, en el sistema normativo de Yahad, que también fue utilizado por grupos helenísticos (2000: 50).

La segunda propuesta tiene en cuenta los cambios históricos y sus reflejos sociales. Uno de los investigadores que más se ha destacado en la presentación de esta relación es Albert Baumgarten. Para él, la formación de los reinos helenísticos proporcionó el fin de la persecución de segmentos políticos en competencia, que a partir de entonces se organizarían en "sectas" de matriz griega. El entorno en el que se habrían desarrollado era urbano, lo que habría proporcionado "más o menos el mismo tipo de personas, en un entorno equivalente y en circunstancias similares” (1998: 109). Estas condiciones habrían proporcionado todo un aparato social e ideológico que habría sido utilizado por los grupos griegos y, quizás después, los de matriz judía. Es con base en esta perspectiva que el autor cree que se pueden encontrar los elementos de aproximación entre los grupos judíos y grecorromanos. Al tratar con los esenios, por ejemplo, dice lo 
siguiente: "para encontrar equivalentes más exactos del comportamiento esenio, debemos dirigir nuestra atención al dominio de la imaginación, a las utopías griegas" (1998: 101). El trabajo de Baumgarten es muy importante para enmarcar a los grupos judíos y grecorromanos en un entorno social más amplio. Desde una perspectiva que privilegia lo social (en lugar de señalar una espontaneidad en la elaboración de sus estructuras), no hay duda de que los elementos de capacitación de esos grupos se seleccionaron principalmente del entorno urbano, pero el mérito de Baumgarten radica en relacionarlos con la cultura grecorromana.

La última propuesta para dilucidar la proximidad entre los grupos de la época se encuentra en el trabajo del historiador estadounidense Yonder M. Gillihan. Su objetivo general es explicar la ideología y organización cívica de Yahad comparándola con otros grupos judíos y grecorromanos. Para él, lo que promovió las similitudes de ellos fue el hecho de basaren en estándares creados por el Estado. Habrían "prestado términos y normas de las políticas locales y los imperios helenístico y romano, incluida la terminología de gobernantes, cultos oficiales, cuerpos legislativos, tribunales, consejos deliberativos, unidades militares y otros" (2012: 2). Los procedimientos internos también se habrían basado en las disposiciones del Estado, incluido el sistema legal y judicial. Por lo tanto, las similitudes entre los grupos se basarían en lo que Gillihan llama "lenguaje del Estado" (2012: 3), que, según el lugar y la forma de actuar, proporciona el material cultural necesario para la formación de los grupos: eso habría ocurrido en todo el Mediterráneo Oriental desde la creación de grandes unidades sociales integradas.

Sería muy pretencioso decir que hubo solo un medio responsable por aproximar las características compartidas por todos los grupos judíos y grecorromanos. Las propuestas presentadas anteriormente pueden ser válidas para algún aspecto específico (como elementos literarios, lingüísticos e incluso organizativos). Sin embargo, la mayor dificultad en todos ellos es presentar cómo este grupo receptor habría disfrazado los elementos constitutivos de otros grupos o esferas del poder estatal. El horizonte de estas propuestas es el mismo: presentar un escenario en el que las "influencias" fueron responsables de componer la representatividad de esos grupos. Cada uno de ellos, "libremente", se habría apropiado de esos elementos porque son interesantes, convenientes, quizás apropiados para la elaboración de sus estructuras en el momento en que se institucionalizaron.

\section{Política y Delimitación Representativa de los GRupos Judíos}

A diferencia de los autores antes mencionados, propongo un análisis sociopolítico que enumera todas las actividades de esos grupos sin distanciarlos de las tensiones sociales y las presiones políticas que, como veremos, fueron responsables por delimitar sus experiencias religiosas y sociales. Supongo que hubo un agente superior de regulación social que sometió a esos grupos, interfiriendo y limitando sus acciones, pero promoviendo patrones de desempeño más o menos regulares. En el centro, dónde provenía la regulación, estaba el poder soberano, guardián de monopolios y organizador de la sociedad.

Ahora debemos buscar información en las fuentes para que esta propuesta alcance su valor. El mayor interés debe residir en la búsqueda de elementos que puedan señalar la relación entre los grupos con el poder soberano. Selecciono dos partes de documentos para analizar. El primero se refiere a una carta enviada por el apóstol Pablo al grupo judeocristiano y gentil en la ciudad de Corinto. El segundo es un texto que perteneció al grupo que escribió parte de los Rollos del Mar Muerto, conocido como Yahad. Miremos el texto paulino, en la perícopa de 1 Corintios 6: 1-8:

Si alguno de ustedes tiene un pleito con otro, ¿Cómo se atreve a presentar demanda ante los inconversos, en vez de acudir a los creyentes? ¿Acaso no saben que los creyentes juzgarán al mundo? Y, si ustedes han de juzgar al mundo, ¿Cómo no van a ser capaces de juzgar casos insignificantes? ¿No saben que aun a los ángeles los juzgaremos? ¡Cuánto más los asuntos de esta vida! Por tanto, si tienen pleitos sobre tales asuntos, ¿Cómo es que nombran como jueces a los que no cuentan para nada ante la iglesia? Digo esto para que les dé vergüenza. ¿Acaso no hay entre ustedes nadie lo bastante sabio como para juzgar un pleito 
entre creyentes? Al contrario, un hermano demanda a otro, iy esto ante los incrédulos! En realidad, ya es una grave falla el solo hecho de que haya pleitos entre ustedes. ¿No sería mejor soportar la injusticia? ¿No sería mejor dejar que los defrauden? Lejos de eso, son ustedes los que defraudan y cometen injusticias, iy conste que se trata de sus hermanos!

Una primera lectura señala el enfoque religioso dado por Pablo en la relación entre la justicia del grupo ("divina") y la justicia promovida por los tribunales externos, probablemente vinculados a la estructura del poder soberano. Él dice que los tribunales del grupo tendrían el poder de juzgar el "mundo" e incluso los “ángeles”. Si eliminamos el barniz de la religión, podemos ver mejor las razones de su mandato. Pablo era muy consciente de la existencia de poderes externos que podrían interferir con la jurisdicción de los grupos judeocristianos y gentiles vinculados a él. Él mismo ya había pasado por un juicio en la corte judía más importante, el Sanedrín (Hch 23). Aun así, impone límites a la apelación de los miembros en cualquier tribunal fuera del grupo.

Desde el punto de vista paulino, la relación entre sus grupos con el poder temporal fue permitida por su dios hasta cierto punto, con las propias instituciones de poder soberano provenientes de la voluntad divina (un elemento teológico común entre los grupos del período). Si relacionamos este texto con las exhortaciones en otras cartas paulinas dirigidas a grupos judeocristianos y gentiles, nos damos cuenta de que la relación permitida con las instituciones de la sociedad se presentaba solo en un contexto que no entraba en conflicto con sus disposiciones, como el pago de impuestos y el respeto por las autoridades superiores del Estado (Ro 13: 1-7). Cualquier otro problema relacionado con la violación de los preceptos religiosos y sociales señalados por la estructura del grupo debe ser llevado exclusivamente a sus propias autoridades judiciales.

La segunda fuente a considerar es el texto utilizado por el grupo Yahad, conocido como Documento de Damasco (CD). En 9: 1, se describe lo siguiente: "Cualquier hombre que dedique al anatema a cualquiera entre los hombres por las leyes de los gentiles debe ser ejecutado”. El pasaje es corto, pero extremamente significativo. Los investigadores señalan el texto como una paráfrasis tomada del libro bíblico de Levítico. En esto, el texto se presenta de la siguiente manera: "Ninguna persona así consagrada (al anatema) podrá ser rescatada, sino que será condenada a muerte” (27:29). La formulación del original en hebreo, de hecho, muestra la dependencia que el escritor del grupo tenía del texto levítico. ${ }^{15}$ Sin embargo, agrega al final, el pasaje "por las leyes de los gentiles". Ya se ha intentado señalar que esta adición también se extrajo del libro de Levítico, de partes que hablan de no tener contacto con las naciones en oposición a los israelitas, quizás el texto 20: 23, que dice: "no vivan según las costumbres (estatutos) de las naciones" (Gillihan, 2012: 193). Mi posición, sin embargo, es que el escritor reformuló Levítico 27: 29 con el fin de dirigirlo exclusivamente a su grupo (considerado el "verdadero Israel") y justificar, por un punto de vista religioso-normativo, su nueva berit de extensión comunitaria.

La búsqueda de la autonomía de Yahad se ha relacionado con el grupo desde su nacimiento. Como sugiere la investigación actual, este grupo provenía de los esenios, pero aún cultivaba el contacto con los otros grupos de orientación esenia, nombrados en sus escritos como "campamentos" o "asambleas" (CD 12: 22-23). En cada uno de los campos había un cuerpo legislativo y judicial responsable de hacer cumplir las reglas (CD 14: 3-21), pero parece haber una mayor distancia legal de Yahad a ellos. Esto ya se habría esbozado en su período de formación. La Yahad creó sus bases institucionales con una ruptura político-religiosa que ocurrió en la primera mitad del siglo II a.C., eso provocó que un grupo legal fuera al desierto en busca de crear un nuevo "camino" en la religión y salvaguardar su propia existencia, amenazada en ese momento por el poder soberano que se instituyó en Judea (CD 1: 11), a saber, el gobierno expansionista de los Macabeos.

Así como con los grupos judeocristianos y gentiles bajo la autoridad de Pablo, la Yahad disputó con tribunales externos la legitimidad en el trato con la justicia para con sus miembros. Desarrolló códigos penales para regular su estructura interna. Estos códigos muestran la autonomía que tenían los líderes de grupo al tratar con los miembros. Describen algunas infracciones que podrían ser motivo de juicio en los tribunales judíos porque también se conocen en tradiciones bíblicas, como la profanación del nombre divino (1QS 6: 27-72), conducta sexual inapropiada después del matrimonio (4QDe, frag. 7, col. 1, vv. 12-13) y, más 
generalmente, la transgresión contra las leyes de Moisés (1QS 8: 21-23), leyes que todavía estaban presentes en la sociedad judía hasta el siglo I d.C., como podemos ver en las fuentes judías y judeocristianas. En todos estos casos, las autoridades de Yahad parecían ser responsables del juicio, y se descartó cualquier participación de tribunales externos. Dedicar "al anatema entre los hombres por las leyes de los gentiles" significaba usar los tribunales de justicia reconocidos por el Estado (pero no por el grupo) para resolver cualquier disputa dentro del grupo.

La conclusión más objetiva que podemos extraer de las dos fuentes consideradas anteriormente es que ningún miembro de esos grupos podría apelar ante los tribunales "gentiles", o sea, a las autoridades no designadas por los propios grupos. Tampoco podían reclamar el uso de leyes externas para resolver conflictos entre sus miembros que ocurrieron dentro de ellos. ¿Cuál es el propósito de esto? Si los individuos pudieran recurrir a leyes y tribunales externos, el poder que emanaba de las autoridades de esos grupos se rompería, socavando sus barreras legales e institucionales y debilitando su identidad ante la sociedad, poniendo en riesgo su propia existencia como institución proveedora de salvación. Ellos reclamaron no solo el control de los bienes de salvación (Heilsgütern) para los asociados, sino también el poder sobre su propia estructura, que fue reconocida y se dio a conocer como una institución autónoma y singular en medio de la sociedad.

Saber que tales grupos buscaron autonomía y que reconocieron el poder que emanaba de otras fuentes es solo una parte de lo que necesitamos para lograr nuestro objetivo. El punto esencial es comprender que había una tensión entre el poder que emanaba de los grupos y el poder soberano. Si profundizamos en la consideración de las fuentes, podemos encontrar apuntamientos aún más esclarecedores. Podemos volver a utilizar el pequeño e importante texto del CD 9: 1. La parte final muestra que cualquiera que apelara a las leyes gentiles sería "ejecutado". Esta conclusión fue copiada de la misma manera que en el texto de Levítico 27:29. Sin embargo, su uso nos lleva a cuestionar si, de hecho, los líderes de Yahad podrían usar la pena de muerte como castigo para los miembros infractores. Sobre la base de los propios textos del grupo, principalmente sus códigos penales, es posible concluir que no utilizaron la pena de muerte como castigo. En el código penal del libro 1QRegla de la Comunidad (6: 24-7: 25), el más extenso de todos los Yahad, la pena utilizada para castigar a los transgresores que cometieron las transgresiones más graves fue la expulsión.

La misma medida fue tomada por los grupos judeocristianos y gentiles encabezados por Pablo. La carta de 1 Corintios puede ayudarnos a comprender su posición. Veamos la sección 5: 1-5.

Es ya del dominio público que hay entre ustedes un caso de inmoralidad sexual que ni siquiera entre los paganos se tolera, a
saber, que uno de ustedes tiene por mujer a la esposa de su padre. ¡Y de esto se sienten orgullosos! ¿No debieran, más bien,
haber lamentado lo sucedido y expulsado de entre ustedes al que hizo tal cosa? [...] Cuando se reúnan en el nombre de nuestro
Señor Jesús, y con su poder yo los acompañe en espíritu, entreguen a este hombre a Satanás para destrucción de su naturaleza
pecaminosa a fin de que su espíritu sea salvo en el día del Señor.

Los límites impuestos por el poder soberano al grupo judeocristiano y gentil corintio no eran diferentes de los que existían para Yahad. Para Pablo, la inmoralidad fue una grave transgresión. El hombre que lo cometió debe ser "expulsado" del grupo corintio. ¿Qué significaba eso entre ellos? La pena capital dirigida por Pablo por graves transgresiones fue la expulsión del grupo, simbolizado en el texto por "entreguen a este hombre a Satanás”. Esta perspectiva religiosa imputada a una experiencia social tenia a la expulsión como la pérdida del favor divino y de lo reconocimiento del grupo al que pertenecía.

La experiencia religiosa y social de esos grupos tenía que ser dirigida de una manera que evitara en lo posible cualquier conflicto con el entorno social y principalmente con el poder soberano que tenía dominio sobre los monopolios (especialmente los de política y violencia). Tal actitud los protegió de la fricción contra las autoridades externas y con los no miembros, además de regular la interacción con ellos fuera de su dominio. La pena de muerte, por ejemplo, no puede imputarse entre ellos. En Judea, desde el gobierno de los macabeos hasta el siglo I d.C. (una época en la que todos los grupos mencionados anteriormente estaban activos), el gobierno era el que tenía el poder legal para castigar a las personas con la muerte. El juicio de Jesús de Nazaret refleja bien este límite. Según fuentes judeocristianas, el gobernador Poncio Pilato pregunta: “¿Y qué voy a 
hacer con Jesús, al que llaman Cristo?” Todos respondieron (sacerdotes y ancianos): “CCrucifícalo!” (Mt 27: 22-23). ¿Quién sería responsable de la crucifixión del Nazareno? La respuesta la da el evangelista Juan: "Pues llévenselo ustedes y júzguenlo según su propia ley - les dijo Pilato. Nosotros no tenemos ninguna autoridad para ejecutar a nadie - objetaron los judíos" (18:31).

Estos grupos no podían imponer penas severas, como la pena de muerte, a sus miembros. Sabemos esto de los Rollos del Mar Muerto, de los escritos de Josefo, de los textos judeocristianos y mishnáicos del siglo I d.C. Así, la práctica de la expulsión en sí misma puede verse como una experiencia religiosa y social común entre ellos, practicado por todos y sin haber sido "copiado" el uno por el otro. Como con otras prácticas y representaciones, la expulsión se generó y se presentó como similar gracias a las limitaciones impuestas por los poderes externos.

Las experiencias sociales resultantes de la tensión entre el poder soberano y los diversos grupos se transmutaron en un orden divino; comenzando, desde ese momento, para componer una imagen de las experiencias religiosas internas. Para David Flusser (2007: 300-301), fueron las expectativas mesiánicas las que hicieron que esos grupos mantuvieran el respeto por las autoridades civiles. Como el fin de los tiempos era inminente, era necesario mantener un "pacifismo condicionado", teniendo en cuenta que todavía existían gobiernos profanos porque encajaban en una periodización divinamente orientada. Ellos no tenían poderes suficientes para actuar contra las limitaciones impuestas por los gobiernos soberanos. Por esta razón, cualquier venganza necesaria se llevaría a cabo en el momento del fin, por las manos de dios (Ro 12:19). El mensaje de Pablo a los cristianos romanos dejó muy claro que "todos deben someterse a las autoridades públicas... así que las que existen fueron establecidas por él (Dios). Por lo tanto, todo el que se opone a la autoridad se rebela contra lo que Dios ha instituido" (Ro 13: 1-2). De manera similar, el pasaje de la Guerra de los Judíos 2: 140, que dice: "Él siempre mostrará fidelidad a todos los hombres, especialmente a aquellos con autoridad, ya que nadie obtiene un gobierno sin la ayuda de Dios", ha sido visto por muchos eruditos como una descripción del respeto de los esenios por las autoridades del poder soberano (Flusser, 2007: 229).

Para dejar aún más claro que las similitudes entre los grupos de ese período fueron el resultado de los límites impuestos por el poder soberano, debemos analizar lo que no podían hacer en lugar de lo que podían. Josefo menciona algunos movimientos de naturaleza político-religiosa que no lograron consolidarse como grupos jerárquicamente organizados debido a la forma en que sus representaciones se presentaron al entorno social en su génesis. Uno de esos casos fue el del líder mesiánico Teudas (AJ 20: 97-98). Según Josefo, Teudas, que se consideraba un profeta que abriría las aguas del río Jordán. Sin embargo, antes de que lo lograra, él y sus seguidores fueron atacados por sorpresa por orden del gobernador Cuspio Fado, de Judea (44-46 d.C.). Muchos de ellos fueron asesinados. Teudas, después de ser capturado, le cortaron la cabeza. Este fue ciertamente un movimiento bien conocido, ya que Lucas también lo mencionó en Hechos (5: 36). ${ }^{16}$ Otro ejemplo fue el de un judío que había regresado a Jerusalén desde Egipto y, por lo tanto, fue llamado por Josefo (y por Lucas, en He 21:38) como el “egipcio” (GJ 2:261-263, AJ 20: 169-172). Después de decir que entraría en la ciudad de Jerusalén con ayuda divina, él y sus seguidores fueron atacados por las fuerzas romanas. La mayoría fueron asesinados y el movimiento se disipó. ${ }^{17}$

Está claro que esos grupos deben considerarse desde una perspectiva política, lo que demuestra el choque entre diferentes segmentos con el poder soberano de la época. De hecho, el mensaje religioso en sí mismo se presentó como un discurso político, y tal vez uno de oposición. Las acciones de líderes como Teudas y el egipcio fueron una amenaza para el orden establecido y la reacción para ellos fue inmediata. Sin embargo, estos grupos comprendían también entidades políticas y religiosas de contestación, pero esto no significó que todos estaban interesados en colisionar con el poder soberano hasta el punto de ser aniquilados. Por ejemplo, teníamos a Yahad como un grupo bien establecido (hasta la destrucción de su centro ceremonial por las fuerzas romanas en el año 67 d.C., en la guerra nacional contra los romanos) y el desarrollo de grupos judeocristianos. Grupos como lo de Teudas y el egipcio no alcanzaron la etapa de "sedentarización", o sea, no se han desarrollado hasta el punto de crear una estructura física e ideológica organizada y duradera. Justo 
en su nacimiento, privados de la noción de que las experiencias grupales relacionadas con el entorno social, se enfrentaron con el poder soberano.

Como se considera aquí, es posible ver claramente que los elementos que penetraron los límites legales y sociales de los grupos estaban sujetos a la presión directa del poder soberano. Sin embargo, uno no debería pensar que fue solo cuando hubo un estrecho contacto entre los grupos y la sociedad, como en sus sistemas judiciales y acciones sociales, que las limitaciones del poder soberano los hicieron acercarse a sus experiencias. Los elementos internos que constituyeron experiencias religiosas, que pueden parecer creados sin depender de otra cosa que no sea la creatividad, también se originaron sobre la base de limitaciones externas. Esta tensión influyó, por ejemplo, en su propia teología. Podemos citar la explicación creada por algunos de ellos al tratar con miembros que cometieron infracciones graves. En un momento en que los líderes de los grupos no tenían la autoridad suficiente para castigar a ninguno de sus miembros, por entrar en conflicto directo con el poder soberano, se invocó la participación divina para tratar con el transgresor. Estaba "muerto", pero no físicamente sino espiritualmente. Se llamaron a las cortes celestiales y el destino del infractor/pecador fue, en ese momento, decidido por el juez primordial, dios. ${ }^{18}$

Los ejemplos considerados anteriormente, basados en las fuentes del período, son importantes para comprender los límites de las experiencias religiosas y sociales y, dado que no hubo una separación delimitada de estos dos campos. Ahora, vale la pena preguntar: ¿es posible decir que las imposiciones del poder soberano eran válidas para todos los grupos de matriz judía y grecorromanos? Hablamos anteriormente sobre el florecimiento de grupos que habrían comenzado a partir del siglo II a.C., en la región de Judea. Esto estaba relacionado con el proceso de centralización política que tuvo lugar a un nivel político más amplio, en el Mediterráneo Oriental, con los gobiernos helénicos del siglo III a.C., y aumentando su intensidad hasta el dominio romano (Elias, 2000: 105). Por esta razón, ciertos segmentos sociales que hasta entonces disputaban los monopolios del poder se redujeron a la situación de los grupos de oposición o fueron aniquilados. En el territorio de Judea, esto sucedió con un gobierno nativo fuerte, el de los Macabeos, que aprendieron mucho con sus predecesores helenísticos de Egipto y principalmente de Siria, que dominaron la región desde finales de siglo IV a.C. hasta la primera mitad del siglo II a.C.

Frente a gobiernos cada vez más centralizados y unificados, el reglamento de los grupos nacientes ahora está relacionado con lo que sucedía en los círculos centrales de los que emanaba el poder soberano. Por lo tanto, es posible afirmar que todos los grupos estaban sujetos a las mismas tensiones e imposiciones presentes en una amplia red de interdependencia que interconectaba a las sociedades. Limitándonos a grupos de matriz judía, podemos concluir que las similitudes entre sus experiencias religiosas y sociales ocurrieron por la razón de que no podían ir más allá de los límites de esta cadena en la que el poder soberano estaba presente. Teudas y el egipcio no tenían conciencia de esto. Pablo, por otro lado, tenía mayor destreza en lidiar con los conflictos.

Una secuencia cercana de eventos históricos sorprendentes condujo a una disminución drástica en la pluralidad de grupos judíos. Las dos grandes guerras judías contra los romanos (66-74 d.C. y 132-136 d.C.) y la destrucción del Segundo Templo de Jerusalén (70 d.C.) eliminaron de la escena a los grupos que tenían profundas expectativas mesiánicas, llamadas "apocalípticas", que imputaron una fuerte militancia política con el elemento religioso. En medio de esto, los sabios rabinos de orientación farisaica llevan a cabo su trabajo en Yavne, entre fines de siglo I d.C. y principios de siglo II d.C., comenzando la estandarización del judaísmo frente a la pequeña variedad que sobrevivió a las catástrofes infligidas por los romanos. ${ }^{19}$

\section{Conclusiones}

El enfoque aproximado, siguiendo las tendencias históricas más recientes que buscan integrar diferentes unidades sociales, ha sido muy positivo al proporcionar resultados que no separan el objeto de las tensiones sociales existentes en medio de las redes de interdependencia de las sociedades. Aún más que eso, los elementos particulares apuntan a cambios en aspectos más amplios, que sirven como indicadores sociales del proceso 
civilizador de toda la sociedad (Elias, 2000). Aplicando esto a los grupos judíos del período considerado, vemos que no solo sus experiencias religiosas y sociales se volvieron uniformes, sino que el poder centralizado era lo suficientemente fuerte para no permitir que los principales monopolios de la constitución del Estado estuvieran disponibles como bienes de competición.

En ese contexto, lo que llamamos "judaísmo" era, de hecho, una base cultural común que estaba presente en la formación de diferentes grupos. En el campo religioso no había unidad, al mismo tiempo que lo religioso no puede ser visto como un campo separado de lo político. Por lo tanto, su desempeño social estaba necesariamente vinculado a las decisiones políticas que pasaban por las redes de interdependencia en las que estaban posicionados, promoviendo limitaciones directas en sus experiencias religiosas y sociales. Al final, las similitudes en sus experiencias deben entenderse no como resultado de su espontaneidad y autonomía, ni como resultado de préstamos, sino como resultado de una regulación existente en toda la sociedad.

\section{FuenTES}

Coogan, M. D. (2001) The New Oxford Annotated Bible: New Revised Standard Version with the Apocrypha. 3 ed. Oxford: Oxford University Press.

Garcia Martínez, F. \& Tigchelaar, E. J. C. (1997). The Dead Sea Scrolls Study Edition. Leiden: Brill.

Santa Biblia. (1999). Nueva Versión Internacional. Miami: Editorial Vida.

Whiston, W. (2003).Josephus: The complete works. Nashville: Thomas Nelson Incorporated.

Yonge, C. D. (1991). The works of Philo: Complete and Unabridged (New updated Edition). Peabody (MA): Hendrickson Publishers.

\section{OBRAS DE REFERENCIA}

Schiffman, L. \& Vanderkam J. C. (Eds.). (2000). Encyclopedia of the Dead Sea Scrolls. New York: Oxford University Press.

\section{Bibliografía}

Baumgarten, A. L. (1997). The flourishing of Jewish sects in the Maccabean era: an interpretation. Leiden: Brill.

Baumgarten, A. L. (1998). Graeco-Roman voluntary associations and ancient Jewish sects. En M. Goodman (Ed.). Jews in a Graeco-Roman world (pp. 93-112). NY: Oxford.

Beall, T. S. (1998). Josephu's description of the essenes ilustrated by the Dead Sea Scrolls. New York: Cambridge University Press.

Burns, J. E. (2006). “Essene sectarism and social differentiation in Judaea after 70 c.e.” HTR, Cambridge, v. 99, n. 3 , pp. 247-274.

Chartier, R. (1988). Cultural History: between practices and representations. Trans. Lydia G. Cochrane. New York: Cornell University Press.

Coury, G. (2010). Norbert Elias e a construção dos grupos sociais: da economia psíquica à arte de reagrupar. En A. Garrigou \& B. Lacroix (Eds.). Norbert Elias: a politica e a história (pp. 123-144). São Paulo: Perspectiva.

Elias, N. (2000). The Civilizing Process: sociogenetic and psychogenetic investigations. Trans. Edmund Jephcott. Oxford: Blackwell.

Flusser, D. (2007). The jewish origins of the early church's attitude toward the State. En D. Flusser. Judaism in the Second Temple Period (pp. 299-304). Trans. Azzan Yadin. Grand Rapids (MI): Eerdmans.

Gillihan, Y. M. (2012). Civic ideology, organization and law in the Rule Scrolls: a comparative study of the Covenanters' Sect and contemporary voluntary associations in political context. Leiden: Brill. 
Goodman, M. (2007). Josephus and variety in first-century Judaism. En M. Goodman (Ed.). Judaism in the Roman World (pp. 33-46). Leiden: Brill.

Guarinello, N. L. (2014). Historia Antigua. Sáo Paulo: Contexto

Hengel, M. (1974). Judaism and Hellenism: studies in their encounter in Palestine during the Early Hellenistic Period. Trans. John Bowden. Philadelphia: Fortress Press.

Hengel, M. (2000). Qumran and Hellenism. En J. J. Collins \& R. A, Kugler (Eds.). Religion in the Dead Sea Scrolls (pp. 46-56). Grand Rapids (MI): Eerdmans.

Hillel, N. (2006). Proximity to power and Jewish Sectarian groups of the Ancient Period: A Review of Lifestyle, Values, and Halakhah in the Pharisees, Sadducees, Essenes, and Qumran. Leiden: Brill.

Horsley, R. \& Hanson, J. S. (1985). Bandits, Prophets and Messiabs: popular movements in the time ofJesus. New York: Winston Press.

Neusner, J. (1973). “'By the testimony of two witnesses' in the Damascus Document 9: 17-22 and in Pharisaic-rabbinic law”. RQ, Paris, v. 8 n. 2, 197-217.

Richardson, P. (1991). Law in religious communities in the Roman period: the debate over Torah and nomos in postbiblical Judaism and early Christianity. Toronto: CCSR.

Regev, E. (2004). "Comparing sectarian practice and organization: the Qumran sects in light of the regulations of the Shakers, Hutterites, Mennonites and Amish”. Numen, Leiden, v. 51, n. 2, pp. 146-181.

Schiffman, L. \& Vanderam, J. C. (Eds.). (2000). Encyclopedia of the Dead Sea Scrolls. New Yor: Oxford University Press.

Schniedewind, W. (2004). How the Bible became a book: the textualization of Ancient Israel. New York: Cambridge University Press.

Weinfeld, M. (2005). Normative and sectarian Judaism in the Second Temple Period. New York: T\&T Clark.

Weinfeld, M. (1986). The organization pattern and the Penal Code of the Qumran sect: a comparison with guilds and religious associations of the Hellenistic-Roman period. Göttingen: Vandenhoeck \& Ruprecht.

\section{Notas}

1 Las estructuras políticas judías se considerarán siguiendo el modelo histórico-social procesalista y los conceptos de Norbert Elias (2000), que permiten insertar el contexto social en una larga duración temporal para la comprensión de las transformaciones sociales.

2 Por ejemplo, es difícil decir que la Yahad, formado (como lo indica la investigación más reciente) por disidentes esenios en la primera mitad del siglo II a.C., podría componer un "movimiento" con el mismo alcance que los fariseos, saduceos y esenios. Para este caso, los conceptos que hacen una delimitación más estricta no parecen equivocados.

3 La lista de abreviaturas para los textos bíblicos (de acuerdo con la NVI) y otras fuentes se puede encontrar al final del artículo. Todas las citas bíblicas utilizadas aquí fueron tomadas de la Nueva Versión Internacional. Las citas de otros documentos están presentes en obras presentadas en la sección "fuentes" de este artículo.

4 Ver la opinión disidente de Richard Horsley (1985: 166-173), que a diferencia de lo que se consolidó en la historiografía, no está de acuerdo que la "cuarta filosofía", descrita por Josefo, era un grupo de fanáticos y asesinos a sueldo.

5 La proliferación de grupos no se restringió al territorio de Judea. Los investigadores han encontrado documentos que apuntan a este aumento en toda la región helenística oriental desde el siglo III a.C. En el Mediterráneo romano parece tener habido una expansión aún mayor, con grupos de habla latina y griega (Baumgarten, 1998: 94, 109).

6 Las traducciones de citas en inglés de autores y fuentes son de mi responsabilidad.

7 Los esenios, por ejemplo, son descritos por Josefo (y el filósofo judío-egipcio Filón de Alejandría) como "pacifistas", que buscaban la virtud y la templanza (AJ 15: 379). Pero con el estallido de la guerra contra Roma en el siglo I d.C., algunos de ellos abandonan este posicionamiento y se lanzan contra el enemigo. Este fue el caso de Juan el Esenio, registrado en GJ 2: 567-568.

8 Algunos investigadores ya han advertido que los sesgos utilizados por estos autores pueden ser cuestionados, especialmente porque sus comparaciones están comprometidas con los modelos filosóficos griegos y dirigidas al público de habla griega (EDSS, 2000: 427, v. 1). Cabe señalar, sin embargo, que la dependencia textual de un estándar filosófico y literario, y el hecho de que está dirigida a un público más amplio de habla griega, no promueve ningún desacuerdo con respecto a la proximidad entre los grupos considerados (Goodman, 1998). 
9 Debemos enfatizar que la historia bíblica también fue el resultado de un proyecto arbitrario, político y religioso, de reconstrucción nacional, que tuvo lugar principalmente en el período que siguió al regreso de los judíos al territorio de Judea (siglo V a.C.), después del Exilio babilónico (siglo VI a.C.). La investigación actual muestra que no había unidad entre las tradiciones antiguas (Schniedewind, 2004). Por esta razón, como proyecto de presente y futuro, las generaciones que se encargaron de esta construcción eliminaron el rico sincretismo de los tiempos del Primer Templo de Jerusalén (siglos X al VI a.C.).

10 Para Horsley (1985: 38-41), el Templo de Jerusalén representaba, de hecho, un "Estado Templo", ya que el cargo de sacerdote comenzó, desde la usurpación de Jonatán Macabeo en 152 a.C., a tener función política y religiosa (que duraría hasta el final de la dinastía macabea en 37 a.C.). Aunque el papel político del Templo disminuyó con el final de la dinastía macabea, el Templo siguió siendo un lugar de toma de decisiones políticas y religiosas.

11 Para Baumgarten (1998: 106), "Jerusalén y el Templo fueron el foco principal de la actividad sectaria".

12 Aparentemente, esta posición de los esenios estaba relacionada con sus estrictas reglas de pureza ritual o contacto muy cercano con los no esenios (ver la amplia discusión en Beall, 1988: 115-119).

13 Sin embargo, hubo quienes cortaron su asociación con el Templo de Jerusalén. La Yahad rompió relaciones con el Templo porque lo consideraba "contaminado". El grupo impugnó el ascenso de los macabeos al sumo sacerdocio, considerándolos como usurpadores. Esto se puede ver en sus escritos 4QMMT y CD.

14 Cada una de estas similitudes se discute mucho en historiografía y cualquier intento de esbozarlas aquí sería bastante superficial. Para una consideración más específica de estas y otras similitudes, sugiero leer los siguientes trabajos: Harland, P. A. (1999). Claiming a Place in Polis and Empire: The Significance of Imperial Cults and Connections Among Associations, Synagogues and Christian Groups in Roman Asia (c. 27 B.C.E.-138 C.E.). (Ph.D. diss.). University of Toronto: Centre for the Study of Religion. Kloppenborg, J. S. \& Wilson S. G. (Eds.). (1996). Voluntary Associations in the Graeco-Roman World. London: Routledge. Newman, H. (2006). Proximity to Power and Jewish Sectarian Groups of the Ancient Period: a Review of Lifestyle, and Halakhah in the Pharisees, Sadducees, Essenes and Qumran. Leiden: Brill. Richardson, P. \& Westerholm. S. (Eds.). (1991). Law in religious communities in the Roman period: the Debate Over Torah and Nomos in Post-biblical Judaism and Early Christianity. Ontario: WLU Press. Stern, S. (Ed.). (2011). Sects and sectarianism in Jewish history. Leiden: Brill. Van Nijf, O. M. (1997). The Civic World of Professional Associations in the Roman East (Dutch Monographs on Ancient History and Archaeology 17). Amsterdam: Gieben.

15 Para una comparación entre los textos hebreos, sobre todo en su ortografía, sugiero la lectura de Gillihan (2012: 192-193).

16 Aunque la referencia a él en el libro de los Hechos es cronológicamente errónea.

17 Otro grupo mencionado por Josefo y también encontrado en fuentes judeocristianas es el de los bautistas, que se reunieron alrededor de Juan el Bautista. Aunque Juan Batista fue asesinado, su grupo continuó actuando (como sucedió con el Maestro de Justicia y Jesús de Nazaret), lo que nos puede decir que el problema que involucra a estos líderes y poderes estatales fue menos excesivo que el de Teudas y el egipcio (AJ 18: 116-119, Lc 3: 1-21).

18 Esto fue lo que sucedió en grupos como Yahad y los judeocristianos. Según Jacob Neusner (1973), la misma actitud fue tomada por los grupos bajo la dirección de sabios rabinos del siglo I d.C.

19 Hay un silencio de las fuentes, especialmente en el Talmud, sobre la supervivencia de otros grupos judíos después de la Primera Guerra Judía. Esto es muy consistente con la configuración religiosa que se estableció después del conflicto, ya que el grupo de fariseos fue el que "sobrevivió" con el mayor número de individuos. En la opinión de Joshua E. Burns (2006: 251-260), los judíos de otros grupos sobrevivieron a la catástrofe de la guerra, pero no tenían suficiente representación para evitar la estandarización del judaísmo esbozada por los fariseos.

\section{BY-NC-SA}

